\title{
PI3K/AKT/mTOR pathway in pulmonary carcinoid tumours
}

\author{
ZIXUAN ZHANG and MENGZHAO WANG \\ Division of Respiratory Medicine, Peking Union Medical College Hospital, Peking Union Medical College, \\ Chinese Academy of Medical Sciences, Beijing 100730, P.R. China
}

Received October 19, 2015; Accepted March 17, 2017

DOI: 10.3892/ol.2017.6331

\begin{abstract}
The present study examined the expression of mammalian target of rapamycin (mTOR) and mutations in the phosphoinositide 3-kinase (PI3K)/AKT/mTOR pathway in 54 patients with typical carcinoid tumours (TC) or atypical carcinoid tumours (AC). In total, 54 bronchopulmonary neuroendocrine tumour (NET) surgical specimens, consisting of $17 \mathrm{TC}, 8 \mathrm{AC}, 17$ large-cell neuroendocrine carcinoma (LCNEC), and 12 small-cell lung carcinoma (SCLC) samples, were tested for mTOR by immunohistochemistry, and 104 exon sites were tested in the PI3K/AKT/mTOR pathway by nested polymerase chain reaction. It was found that the positive rates for mTOR expression in TC/AC and LCNEC/SCLC were $60(15 / 25)$ and $55.2 \%(16 / 29)$, respectively. In total, 4 missense mutations were found in 3 patients with TC/AC, including mutations in exon 48 of mTOR (c.6667C $>$ T), exon 21 of tuberous sclerosis complex (TSC) 1 (c.2765G>A), and exons 12 (c.1265C>T) and 19 (c.2148C >T) of TSC2. To the best of our knowledge, mutations in exon 48 of mTOR and exon 21 of TSC1 have not been previously reported. Tissues from patients with single mutations exhibited strong positive mTOR immunohistochemical staining, and tissues from patients with double mutations were weakly positive. The same mutations were not observed in SCLC or LCNEC. In conclusion, gene mutations were observed and an association between the gene mutations and mTOR expression were indicated in the PI3K/AKT/mTOR pathway in TC/AC tumours. Those mutations may be driver genes and treatment targets.
\end{abstract}

\section{Introduction}

Bronchopulmonary neuroendocrine tumours (NETs) represent a distinct spectrum of tumours and are separated into

Correspondence to: Dr Mengzhao Wang, Division of Respiratory Medicine, Peking Union Medical College Hospital, Peking Union Medical College, Chinese Academy of Medical Sciences, 1 Shuaifuyuan, Dongcheng, Beijing 100730, P.R. China

E-mail: mengzhaowang@sina.com

Key words: pulmonary carcinoid tumours, gene mutation, immunohistochemistry, mTOR inhibition, therapeutic target four subgroups according to the grading concept, as follows: Typical carcinoid (TC) tumour is low-grade; atypical carcinoid (AC) tumour is intermediate-grade; and large-cell neuroendocrine carcinoma (LCNEC) and small-cell lung carcinoma (SCLC) are high-grade. Despite this common classification, these neuroendocrine tumours differ regarding their natural course of disease and treatment strategies, and the five-year survival rates of TC, AC, LCNEC and SCLC are 87, 44, 23 and $2-3 \%$, respectively (1-3).

Mammalian target of rapamycin(mTOR), a serine/threonine kinase, functions as a signal amplifier in the phosphoinositide 3-kinase $(\mathrm{PI} 3 \mathrm{~K}) / \mathrm{AKT} / \mathrm{mTOR}$ pathway $(4,5)$. Activation of mTOR is initiated by ligand stimulation of several different membrane-bound growth factor receptors (6). Abnormal activation of mTOR can delay the G1-S phase transition of the cell cycle and affect the state of the cell, which leads to the occurrence of a wide variety of tumours. Receptor stimulation leads to activation of PI3K, which in turn activates the downstream effector Akt. Akt phosphorylates and suppresses the activity of the tuberous sclerosis complex (TSC) 1 and 2 (7). TSC 2 contains a GTPase-activating domain that forms a complex with TSC1 to inhibit the GTPase Ras-homolog enriched in brain (Rheb), and leads to Rheb-mediated activation of mTOR (8). However, the active mutant Rheb-N153T exhibits low GDP-binding activity, and increased levels of the GTP-bound form are present when compared to the wild-type protein. Rheb-S16 N and Rheb-S16H mutations promote high levels of the GTP-bound and mTOR activation, even in cells that overexpress TSC1/2 (9).

Multiple drugs can be used to inhibit the PI3K/AKT/mTOR pathway and are currently being investigated in clinical trials. Among these novel drugs, the rapamycin derivatives Temsirolimus and Everolimus have been approved by the FDA for the treatment of metastatic renal cell carcinoma (10). In addition, clinical trials using mTOR inhibitors have been performed on several tumour types, including glioblastoma, NET, and endometrial, colorectal, gastric, breast and prostate carcinomas (11-14). The PI3K/AKT/mTOR pathway also has a close association with the occurrence of benign diseases $(15,16)$. For example, mutations in phosphate and tensin homolog can lead to Cowden's syndrome (17), and mutations in the tumour-suppressor genes TSC1 and TSC2 can lead to TSC defects (18) and pulmonary lymphangioleiomyomatosis (19). Pulmonary carcinoid tumours are a type of well-differentiated NET that exhibit Erb-B2 receptor tyrosine kinase 4, platelet derived growth factor receptor $\beta, \mathrm{AKT}$, and FRAP1 DNA 
copy numbers that are increased compared with the average copy number in tumours included in the Tumourscape database (20). Furthermore, the majority of these genes are located in the PI3K/AKT/mTOR pathway. The mTOR inhibitors were reportedly effective in selected patients with $\operatorname{TC} / \mathrm{AC}(21,22)$; however, the mechanism is unclear. Therefore, the present study aimed to examine the expression of mTOR and mutations in the PI3K/AKT/mTOR pathway genes in patients with TC/AC.

\section{Materials and methods}

Patients and tissue samples. In total, 54 NET specimens, consisting of 17 TC, 8 AC, 17 LCNEC and 12 SCLC were obtained from patients who consecutively underwent surgical resection at the Peking Union Medical College Hospital (PUMCH; Beijing, China) between May 2001 and April 2012. All samples were re-evaluated and reclassified according to the 2004 criteria for the WHO classification of tumours (23). No patients had received chemotherapy or radiotherapy prior to surgery. All tumour materials were obtained from primary lung tumours. Clinical information, including patient sex, age, smoking history, tumour size and tumour-node-metastasis (TNM) stages was reviewed for each patient. The present study was approved by the Ethical Committee of Peking Union Medical College Hospital, and written informed consent was obtained from patients.

Immunohistochemistry. Tissue sections (4-mm slide) were deparaffinised and dehydrated in graded xylene and alcohol solutions. Endogenous peroxidase activity was blocked by incubating samples in $3 \% \mathrm{H}_{2} \mathrm{O}_{2}$ for $10 \mathrm{~min}$. Antigen retrieval was performed in an electric-heated thermostatic water bath in pre-warmed antigen retrieval buffer (sodium citrate-hydrochloric acid buffer solution; $\mathrm{pH} 6$ ) at $96^{\circ} \mathrm{C}$ for $15 \mathrm{~min}$. Samples were subsequently cooled at room temperature for $30 \mathrm{~min}$. Samples were incubated overnight at $4^{\circ} \mathrm{C}$ with primary antibodies against mTOR (no. 2983; dilution, 1:100; Cell Signaling Technology, Inc., Danvers, MA, USA) and phosphorylated-mTOR (p-mTOR; no. 2976; clone no. 49F9; dilution, 1:100, Cell Signaling Technology, Inc.). Subsequent to incubation with a secondary antibody (biotinylated anti-mouse IgG antibody; no. BA-9200; dilution, 1:200; Vector Laboratories, Burlingame, CA, USA) for 2 h, 3,3'-diaminobenzidine was used for visualisation. Finally, immunostained sections were serially counterstained with hematoxylin, dehydrated in ethanol and cleared in xylene. Sections of prostate cancer tissue specimens that were known to express mTOR/p-mTOR acted as a positive control. Replacement of the primary antibodies with PBS was used as a negative control.

All paraffin-embedded sections were stained with hematoxylin and eosin for histopathological diagnosis. The intensity of staining was scored as follows: 0, negative (no brown staining); 1, weak (light brown staining); 2 , moderate (intermediate brown staining); and 3, strong (dark brown staining). The extent of staining was scored as $0(<5 \%)$, $1(5-25 \%), 2(26-50 \%), 3(51-75 \%)$ and $4(>75 \%)$ in the cells with respective lesions. The final score was determined by multiplying the staining intensity and the extent of the staining scores, which yielded a range of 0-12. Scores 9-12 were defined as a strong staining pattern $(+++), 5-8$ were defined as a moderate staining pattern (++), 1-4 were defined as a weak staining pattern $(+)$ and 0 was defined as negative expression (-). Sections were considered to be mTOR/p-mTOR-positive if the score was + or higher. Total mTOR and p-mTOR protein expression was independently evaluated by two pathologists, and the results were determined by the consensus of the two pathologists. Inconsistent results were resolved by consultation, or the opinion of a third researcher was sought.

DNA isolation and mutation analysis. Total DNA was isolated from FFPE tissue using deparaffinisation and the QIAamp ${ }^{\circledR}$ DNA FFPE Tissue kit (Qiagen, Dusseldorf, Germany) solution. The present study used nested polymerase chain reaction (PCR) to amplify the extracted genomic DNA. In total, 104 exon sites in the PI3K/AKT/mTOR pathway were tested in NET tissue samples obtained from patients with TC/AC, including exons 9 and 20 of PIK3CA, exons 2-14 of AKT1, exons 3-13 of AKT2, exons 1, 3 and 7 of Rheb, exons 3-22 of TSC1, exons 1-41 of TSC2, and exons 30, 44, 47-54 and 56 of mTOR. Only mutation sites found in patients with TC/AC were further tested in patients with LCNEC or SCLC. The primers spanned the entire exon boundaries, and the sequences of the primers were designed with the Primer Premier software package (version 5.0; Premier Biosoft International, Palo Alto, CA, USA).

PCR was performed using an ABI 9700 PCR thermocycler. In a $25 \mu 1$ reaction mixture, 50-200 ng of genomic DNA was added to $24 \mu \mathrm{l}$ of supermix, $2.0 \mu \mathrm{l}$ of $5 \mu \mathrm{M}$ solutions of forward and reverse primer mixtures, $2.5 \mu 1$ of 10X PCR buffer (Thermo Fisher Scientific, Inc., Waltham, MA, USA), $0.5 \mu 1$ of $10 \mathrm{mM}$ dNTP mixture (Thermo Fisher Scientific, Inc.), $0.8 \mu \mathrm{l}$ of $50 \mathrm{mM} \mathrm{MgCl}_{2}, 0.2 \mu \mathrm{l}$ of Platinum ${ }^{\circledR}$ Taq DNA polymerase (Thermo Fisher Scientific, Inc.), and $18 \mu \mathrm{l}$ of sterilised distilled water. In the first cycle, genomic DNA was denatured at $94^{\circ} \mathrm{C}$ for $5 \mathrm{~min}$. This cycle was followed by 30 cycles at $94^{\circ} \mathrm{C}$ for $30 \mathrm{sec}, 55-58^{\circ} \mathrm{C}$ for $30 \mathrm{sec}$, and $72^{\circ} \mathrm{C}$ for $30 \mathrm{sec}$. The PCR products were subjected to a final extension at $72^{\circ} \mathrm{C}$ for $5 \mathrm{~min}$. In the second cycle, the first cycle PCR products were used as the DNA template, and the components of the remaining reaction mixtures were the same. The mixture was first denatured at $94^{\circ} \mathrm{C}$ for $5 \mathrm{~min}$, followed by 40 cycles at $94^{\circ} \mathrm{C}$ for $30 \mathrm{sec}$, $57-58^{\circ} \mathrm{C}$ for $30 \mathrm{sec}$, and $72^{\circ} \mathrm{C}$ for $30 \mathrm{sec}$, with a final extension at $72^{\circ} \mathrm{C}$ for $5 \mathrm{~min}$. For each tissue sample, the PCR reactions were performed in duplicate and accompanied by a non-template control. The products were purified on a $1.5 \%$ agarose gel, and the purified PCR products were sequenced using forward and reverse primers. Automated sequencing was performed on an ABI 3730XL sequencer.

Statistical analysis. The Pearson $\chi^{2}$ or Fisher's exact test was performed to assess statistical significance of differences between groups. A 2 -tailed $\mathrm{P}<0.05$ was considered statistically significant. All analyses were performed using SPSS statistical software (version 11.5; SPSS, Inc., Chicago, IL, USA).

\section{Results}

Clinical characteristics. The clinical characteristics of 54 patients are summarised in Table I. There was no significant 
Table I. Clinical characteristics of 54 patients.

\begin{tabular}{|c|c|c|c|c|c|c|}
\hline \multirow[b]{2}{*}{ Variable } & \multicolumn{4}{|c|}{ Histological subtype, $\mathrm{n}$} & \multirow[b]{2}{*}{$\chi^{2}$} & \multirow[b]{2}{*}{ P-value } \\
\hline & $\mathrm{TC}$ & $\mathrm{AC}$ & LCNEC & SCLC & & \\
\hline Total & 17 & 8 & 17 & 12 & & \\
\hline Sex & & & & & 3.716 & 0.294 \\
\hline Male & 14 & 4 & 14 & 9 & & \\
\hline Female & 3 & 4 & 3 & 3 & & \\
\hline Age & & & & & 1.473 & 0.688 \\
\hline$\geq 60$ years & 5 & 4 & 8 & 5 & & \\
\hline$<60$ years & 12 & 4 & 9 & 7 & & \\
\hline Smoking history & & & & & 6.012 & 0.111 \\
\hline Yes & 9 & 4 & 15 & 7 & & \\
\hline No & 8 & 4 & 2 & 5 & & \\
\hline Tumour size, $\mathrm{cm}$ & & & & & 20.039 & $<0.001$ \\
\hline$<3$ & 14 & 1 & 4 & 2 & & \\
\hline$\geq 3$ & 3 & 7 & 13 & 10 & & \\
\hline TNM stage & & & & & 21.24 & $<0.001$ \\
\hline $\mathrm{I} / \mathrm{II}$ & 14 & 6 & 10 & 0 & & \\
\hline III/IV & 3 & 2 & 7 & 12 & & \\
\hline
\end{tabular}

TNM, tumour-node-metastasis; TC, typical carcinoid tumours; AC, atypical carcinoid tumours; LCNEC, large-cell neuroendocrine carcinomas; SCLC, small-cell lung carcinomas.

difference between these four groups in sex, age and smoking history. Patients with LCNEC and SCLC exhibited larger tumour sizes and later TNM stages compared with the other groups.

Immunohistochemistry (IHC) results. Staining for mTOR was considered positive when cytoplasmic or membranous staining was observed (Fig. 1). Immunohistochemical results for mTOR expression were not significantly different in the four NET groups $\left(\chi^{2}=3.844, \mathrm{P}=0.6977\right)$. The positive rates for mTOR expression in TC/AC and LCNEC/SCLC were $60 \%(15 / 25)$ and $55.2 \%(16 / 29)$, respectively. There was no association between the clinical characteristics of patients and the mTOR IHC results (Table II). No positive staining was observed for $\mathrm{p}$-mTOR.

Sequencing results. In 25 patients with TC/AC, three mutations were found in mTOR, five mutations were found in TSC1, seven mutations were found in TSC2 and four mutations were found in AKT1. No mutations in PIK3CA, AKT2 or Rheb were observed. Of these mutations, 5 were missense mutations and these mutations included 2 previously reported mutation sites (24), 2 unreported mutation sites and 1 SNP site (Table III). The previously reported mutation sites were present in exons 12 and 19 of TSC2, and the unreported mutation sites were present in exon 48 of mTOR and exon 21 of TSC1 (Fig. 2). Mutations in exon 48 of mTOR and exon 12 of TSC2 were found in the same patient. In total, 12 SCLC and 17 LCNEC specimens were tested for mutations in mTOR, TSC1, TSC2 and AKT1 genes. No mutations were found in these patients.
Table II. Correlation between the clinical characteristics of patients and mTOR immunohistochemistry results.

\begin{tabular}{|c|c|c|c|c|}
\hline \multirow[b]{2}{*}{ Variable } & \multicolumn{2}{|c|}{ mTOR expression, $\mathrm{n}$} & \multirow[b]{2}{*}{$\chi^{2}$} & \multirow[b]{2}{*}{ P-value } \\
\hline & Positive & Negative & & \\
\hline Sex & & & 3.638 & 0.0565 \\
\hline Male & 27 & 14 & & \\
\hline Female & 4 & 9 & & \\
\hline Age & & & 0.8331 & 0.3614 \\
\hline$\geq 60$ years & 11 & 11 & & \\
\hline$<60$ years & 20 & 12 & & \\
\hline Smoking history & & & 0.7128 & 0.3985 \\
\hline Yes & 21 & 13 & & \\
\hline No & 10 & 10 & & \\
\hline Tumour size, $\mathrm{cm}$ & & & 1.347 & 0.2459 \\
\hline$<3$ & 10 & 11 & & \\
\hline$\geq 3$ & 21 & 12 & & \\
\hline TNM stage & & & 0.9523 & 0.8128 \\
\hline $\mathrm{I} / \mathrm{II}$ & 18 & 12 & & \\
\hline III/IV & 13 & 11 & & \\
\hline
\end{tabular}

mTOR, mammalian target of rapamycin; TNM, tumour-node-metastasis.

Association between mTOR expression and gene mutation. These four mutations were found in 3 patients, and this group included 2 atypical carcinoid patients and 1 typical carcinoid patient (Table IV). In total, 2 patients with signalling cascade mutations exhibited strong positive mTOR IHC staining, and the patient with double mutations was weakly positive for mTOR IHC staining.

Survival status. As of December 9, 2015, all patients with TC/AC were still alive, with a median follow-up time of 70 months. Progression had occurred in 1 patient with TC, and the progression free survival (PFS) time was 51 months. Liver metastasis occurred in 1 patient with $\mathrm{AC}$, and the PFS time was 47 months. However, the mean PFS times of patients with LCNEC and SCLC were 10.7 and 5.5 months, respectively.

\section{Discussion}

In the present study, the positive rates for mTOR staining in TC/AC and LCNEC/SCLC were 60\% (15/25) and 55.2\% $(16 / 29)$, respectively. No significant association between mTOR and clinicopathological features was observed. To the best of our knowledge, no studies have investigated the association between mTOR expression and clinical features in bronchopulmonary NETs. However, controversy does exist regarding the results in NSCLCs. Anagnostou et al (25) found the expression of mTOR had no statistically significant correlation with the histological type, sex, age and clinical pathological staging. By contrast, Oh et al (26) studied 574 NSCLC patients and showed that mTOR expression was 
Table III. Gene mutations in TC/AC.

\begin{tabular}{lllll}
\hline Patient number & Gene location & Mutation & Nucleotide change & Type of mutation \\
\hline 7 & mTOR 48 exon & c.6667C $>$ T & p.Gln2222Lys & Missense $^{\mathrm{a}}$ \\
3 & TSC1 21 exon & c.2765G $>$ A & p.Gly922Glu & Missense $^{\text {a }}$ \\
$8 / 19$ & TSC2 10 exon & c.1100G $>$ G/A & p.Arg367Gln & SNPs \\
7 & TSC2 12 exon & c.1265C $>$ T & p.Ser422Phe & Missense \\
5 & TSC2 19 exon & c.2148C $>$ T & p.Ser716Phe & Missense \\
\hline
\end{tabular}

${ }^{a}$ These mutations have not reported in previous studies. mTOR, mammalian target of rapamycin; TSC, tuberous sclerosis complex.
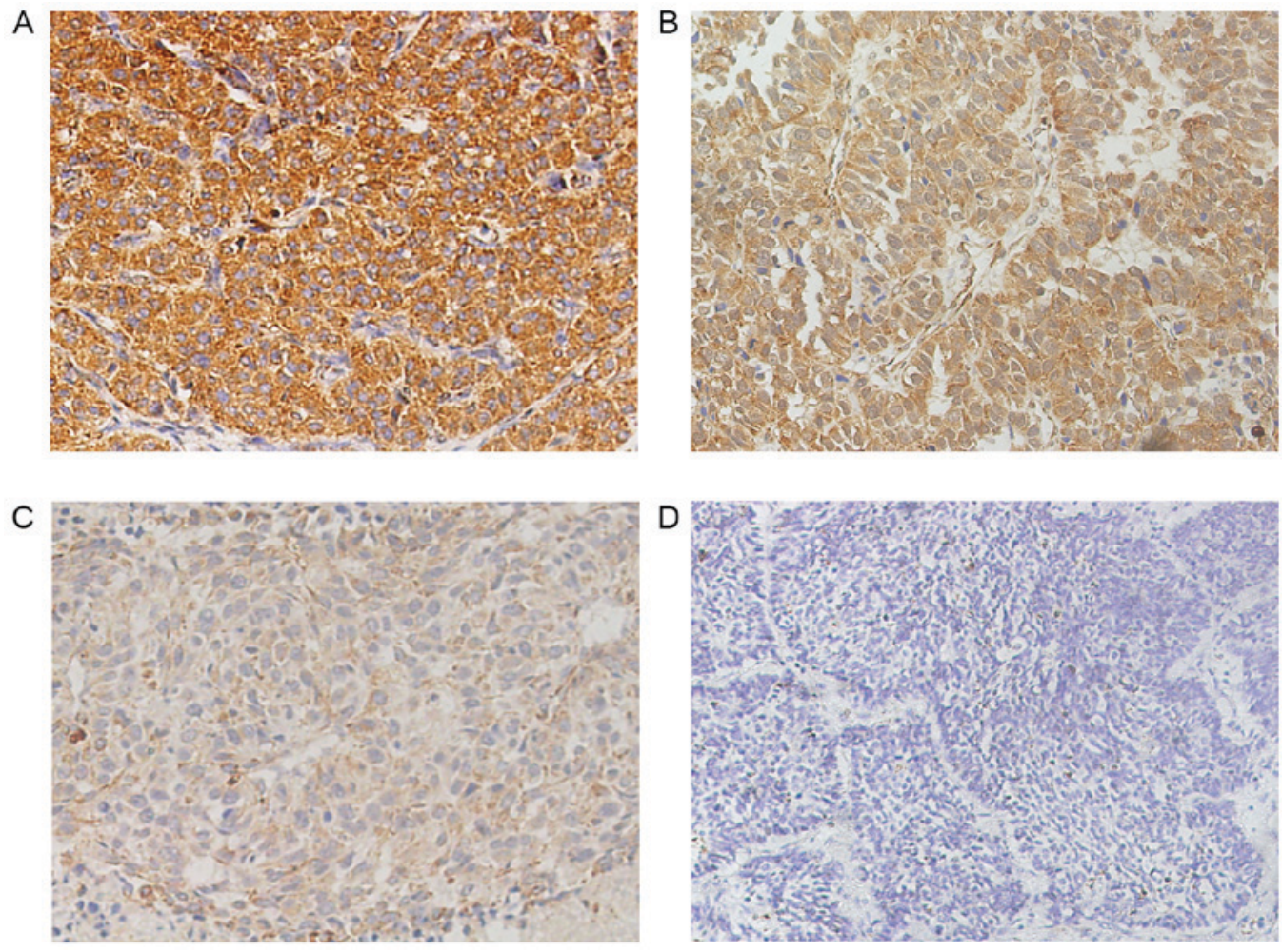

Figure 1. Mammalian target of rapamycin expression in neuroendocrine tumours. Representative images of (A) strong positive staining, (B) moderate positive staining, (C) weakly positive staining and (D) negative staining.

significantly associated with female sex, tumour size $\leq 3 \mathrm{~cm}$, adenocarcinoma, non-smoker status and low pathological stage. Righi et al (27) found decreased expression of active forms of mTOR in high-grade carcinomas (either SCLC or LCNEC) compared with low-to-intermediate grade (either TC or AC). As the p-mTOR epitope is lost during the formalin and paraffin embedding process, no p-mTOR staining was detected in the present experiment.

In traditional cytogenetic studies, comparative genomic hybridisation analyses are used frequently (28-32). Generally, TC/AC exhibited none or only a few aberrations and AC harboured more chromosomal aberrations than TC. In bronchial NETs, Walch et al (28) found DNA gains on chromosomes 1p (4\%), 9q (4\%), and 16p (13\%). Zhao et al (30) analysed 11 patients and showed that one patient lost chromosome $1 \mathrm{p}(9 \%)$ and two patients gained chromosome $9 \mathrm{q}(18.2 \%)$. Ullmann et al (31) found DNA gains on chromosomes $16 \mathrm{p}$ $(8.6 \%)$ and $9 q 34(5.7 \%)$. Warth et al (32) found DNA gains on chromosome $9(17.7 \%)$ and 16p (11.8\%) and DNA losses on chromosome $1 \mathrm{p}(5.9 \%)$. Chromosomal instability is a distinct molecular mechanism that causes DNA mutations, and these mutations underlie the pathogenesis of numerous epithelial tumours. In the present study, four missense mutations were distributed throughout the mTOR, TSC1 and TSC2 genes. These genes are located on chromosome 1p36.22, 9q34.11 and $16 \mathrm{p} 13.3$, respectively, which had been reported frequently in previous studies $(33,34)$. In the present study, two types of mutations were reported for the first time, including the c. $6667 \mathrm{C}>\mathrm{T}$ mTOR exon 48 mutation and the c. $2765 \mathrm{G}>\mathrm{A}$ TSC1 exon 21 mutation. The present study also identified associations between gene mutations and mTOR expression, and those gene mutations may be important in patients with $\mathrm{TC} / \mathrm{AC}$.

In the RADIANT-2 study $(35,36)$, the mTOR inhibitor Everolimus plus Octreotide LAR were studied in advanced lung NETs. In total, 429 patients were enrolled in this study, 
Table IV. Summary of three patients with phosphoinositide 3-kinase/AKT/mTOR pathway gene mutations.

Patient number

\begin{tabular}{|c|c|c|c|}
\hline \multirow[b]{2}{*}{ Mutation } & \\
\hline & 7 & 3 & 5 \\
\hline Location & mTOR 48 exon and TSC 212 exon & TSC1 21 exon & TSC2 19 exon \\
\hline mTOR staining intensity & + & +++ & +++ \\
\hline Pathological type & $\mathrm{AC}$ & $\mathrm{AC}$ & $\mathrm{TC}$ \\
\hline Stage & IIB & IB & IB \\
\hline Diagnosis date & Jan 6, 2006 & Jan 6, 2011 & June 24,2010 \\
\hline Sex & Male & Female & Male \\
\hline Smoking history & Yes & No & Yes \\
\hline Maximum diameter, $\mathrm{cm}$ & 5 & 11 & 0.8 \\
\hline Survival time, months ${ }^{\mathrm{a}}$ & 95.5 & 35.4 & 42 \\
\hline
\end{tabular}

a Survival time was measured until December 19, 2013. AC, atypical carcinoid tumours; TC, typical carcinoid tumours; mTOR, mammalian target of rapamycin; TSC, tuberous sclerosis complex.

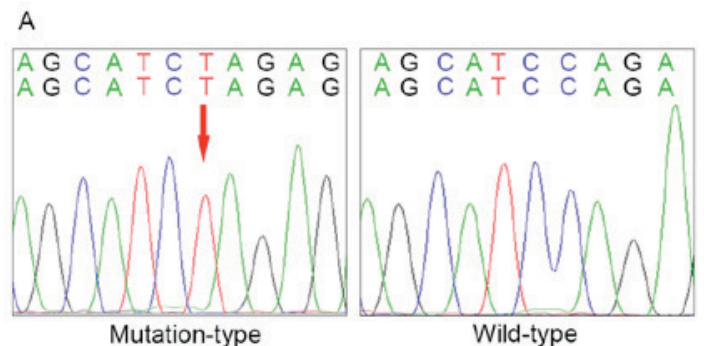

B

C
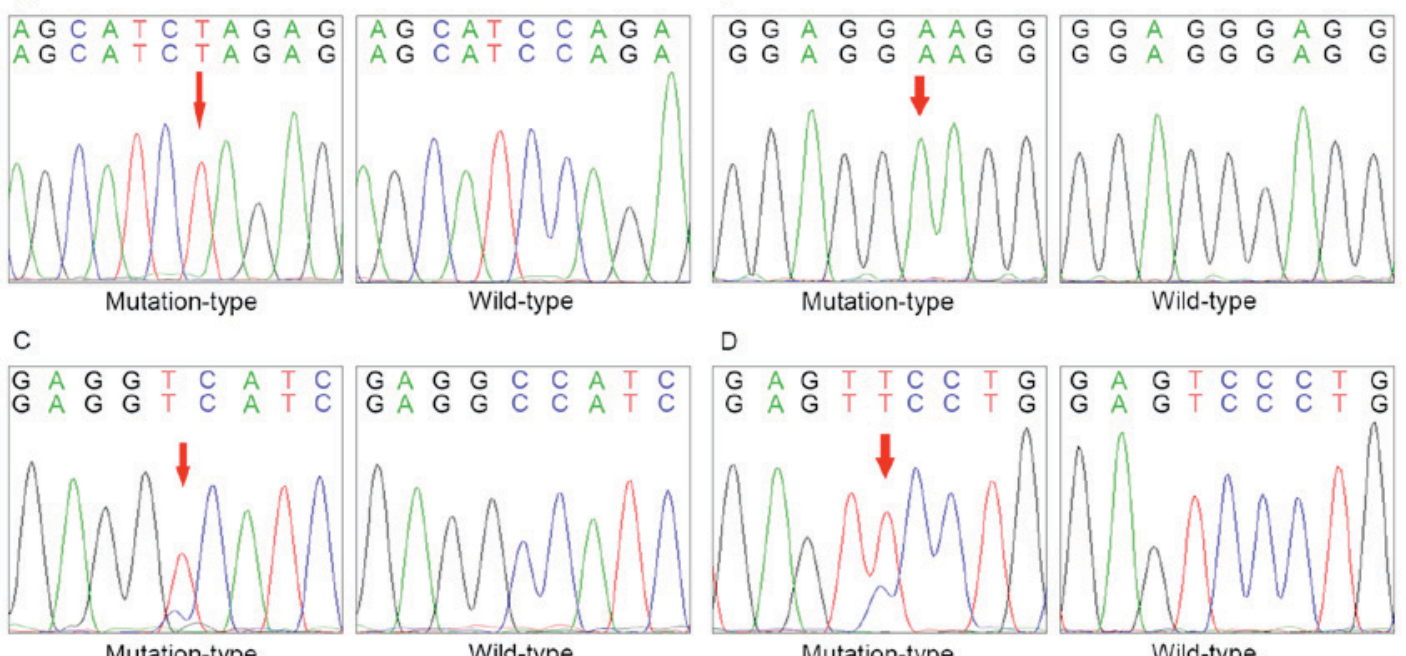

D

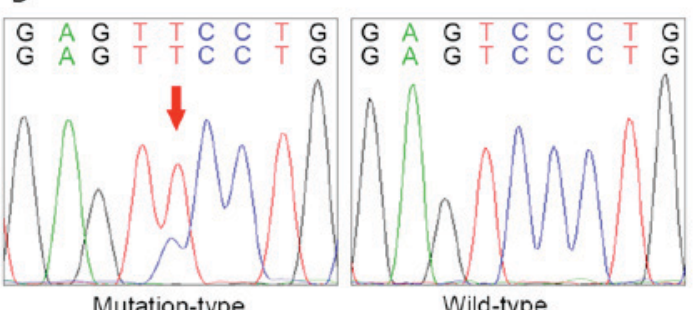

Figure 2. Gene mutation statuses. Mutation sites are indicated by the red arrow. (A) Mammalian target of rapamycin exon 48, c.6667C >T. (B) TSC2 exon 12, c.1265C $>$ T. (C) TSC1 exon 21, c.2765G >A. (D) TSC2 exon 19, c.2148C >T. TSC, tuberous sclerosis complex.

including 44 patients with lung carcinoid tumours. Pulmonary carcinoid subgroup analysis showed that patients who received Everolimus had a longer median PFS time than placebo treated patients (13.6 months vs. 5.6 months). Certain studies have found that mTOR expression and gene mutation can predict the efficacy of mTOR inhibitors. Gagliano et al (22) found that mTOR pathway activation is associated with improved response to Everolimus in vitro. Zatelli et al (37) used Everolimus and SOM230 to address the samples of 24 pulmonary carcinoids. The samples with increased levels of mTOR were always sensitive to Everolimus. In bladder cancer, Iyer et al (38) found unique somatic mutations that were the basis for Everolimus sensitivity. The results showed that $8 \%$ of the patients had TSC1 gene mutations (c.1907_1908del, p.Glu636fs), and patients with TSC1 mutations remained on Everolimus longer than those with wild-type tumours (7.7 vs. 2.0 months, $\mathrm{P}=0.004$ ). Gene mutations in the PI3K/AKT/mTOR pathway may be a treatment target in $\mathrm{TC} / \mathrm{AC}$.
The present study has several limitations. First, the number of patients was small, and the mutations only occurred in 3 patients $(12 \%)$. Since it is a type of tumour with low morbidity, TC/AC requires additional investigation in a wider population. Secondly, since mTOR inhibitor treatment is not allowed for the treatment of TC/AC in China, no patients received $\mathrm{mTOR}$ inhibitor treatment. In conclusion, there are gene mutations in the PI3K/AKT/mTOR pathway in TC/AC, and it indicated an association between these mutations and mTOR expression.

\section{Acknowledgements}

The authors thank Professor Xuan Zeng, Dr Xiaolong Liang and Dr Li Yuan (Peking Union Medical College Hospital, Beijing, China) for their contribution to the data acquisition. The study was supported by Peking Union Medical College Hospital (grant no. S-676). 


\section{References}

1. Travis WD, Rush W, Flieder DB, Falk R, Fleming MV, Gal AA and Koss MN: Survival analysis of 200 pulmonary neuroendocrine tumors with clarification of criteria for atypical carcinoid and its separation from typical carcinoid. Am J Surg Pathol 22: 934-944, 1998

2. Skuladottir H, Hirsch FR, Hansen HH and Olsen JH: Pulmonary neuroendocrine tumors: Incidence and prognosis of histological subtypes. A population-based study in Denmark. Lung Cancer 37: 127-135, 2002.

3. Cooper WA, Thourani VH, Gal AA, Lee RB, Mansour KA and Miller JI: The surgical spectrum of pulmonary neuroendocrine neoplasms. Chest 119: 14-18, 2001.

4. Papadimitrakopoulou V: Development of PI3K/AKT/mTOR pathway inhibitors and their application in personalized therapy for non-small-cell lung cancer. J Thorac Oncol 7: 1315-1326, 2012.

5. Brown EJ, Albers MW, Shin TB, Ichikawa K, Keith CT, Lane WS and Schreiber SL: A mammalian protein targeted by G1-arresting rapamycin-receptor complex. Nature 369: 756-758, 1994.

6. Capdevila J, Salazar R, Halperín I, Abad A and Yao JC: Innovations therapy: Mammalian target of rapamycin (mTOR) inhibitors for the treatment of neuroendocrine tumors. Cancer Metastasis Rev 30 (Suppl 1): 27-34, 2011.

7. Hay N: The Akt-mTOR tango and its relevance to cancer. Cancer Cell 8: 179-183, 2005

8. Rosner M, Hanneder M, Siegel N, Valli A, Fuchs C and Hengstschlager M: The mTOR pathway and its role in human genetic diseases. Mutat Res 659: 284-292, 2008.

9. Sato T, Umetsu A and Tamanoi F: Characterization of the Rheb-mTOR signaling pathway in mammalian cells: Constitutive active mutants of Rheb and mTOR. Methods Enzymol 438: 307-320, 2008

10. Chiang GG and Abraham RT: Targeting the mTOR signaling network in cancer. Trends Mol Med 13: 433-442, 2007.

11. Yao JC,Phan AT, Chang DZ, Wolff RA, Hess K, Gupta S, Jacobs C, Mares JE, Landgraf AN, Rashid A and Meric-Bernstam F: Efficacy of RAD001 (everolimus) and octreotide LAR in advanced low- to intermediate-grade neuroendocrine tumors: Results of a phase II study. J Clin Oncol 26: 4311-4318, 2008.

12. Yao JC, Shah MH, Ito T, Bohas CL, Wolin EM, Van Cutsem E, Hobday TJ, Okusaka T, Capdevila J, de Vries EG, et al: Everolimus for advanced pancreatic neuroendocrine tumors. N Engl J Med 364: 514-523, 2011.

13. Guertin DA and Sabatini DM: Defining the role of mTOR in cancer. Cancer Cell 12: 9-22, 2007.

14. Molinolo AA, Hewitt SM, Amornphimoltham P, Keelawat S, Rangdaeng S, Meneses García A, Raimondi AR, Jufe R, Itoiz M, Gao Y, et al: Dissecting the Akt/mammalian target of rapamycin signaling network: Emerging results from the head and neck cancer tissue array initiative. Clin Cancer Res 13: 4964-4973, 2007.

15. Inoki K and Guan KL: Tuberous sclerosis complex, implication from a rare genetic disease to common cancer treatment. Hum Mol Genet 18 (R1): R94-R100, 2009.

16. Reinke A, Chen JC, Aronova S and Powers T: Caffeine targets TOR complex I and provides evidence for a regulatory link between the FRB and kinase domains of Torlp. J Biol Chem 281: 31616-31626, 2006.

17. Inoki K, Corradetti MN and Guan KL: Dysregulation of the TSC-mTOR pathway in human disease. Nat Genet 37: 19-24, 2005.

18. Young $\mathrm{J}$ and Povey $\mathrm{S}$ : The genetic basis of tuberous sclerosis. Mol Med Today 4: 313-319, 1998.

19. Carsillo T, Astrinidis A and Henske EP: Mutations in the tuberous sclerosis complex gene TSC2 are a cause of sporadic pulmonary lymphangioleiomyomatosis. Proc Natl Acad Sci USA 97: 6085-6090, 2000.

20. Voortman J, Lee JH, Killian JK, Suuriniemi M, Wang Y, Lucchi M, Smith WJ, Meltzer P, Wang Y and Giaccone G: Array comparative genomic hybridization-based characterization of genetic alterations in pulmonary neuroendocrine tumors. Proc Natl Acad Sci USA 107: 13040-13045, 2010.

21. Dong M and Yao JC: mTOR inhibition, a potential novel approach for bronchial carcinoids. Endocr Relat Cancer 18: C15-C18, 2011
22. Gagliano T, Bellio M, Gentilin E, Molè D, Tagliati F, Schiavon M, Cavallesco NG, Andriolo LG, Ambrosio MR, Rea F, et al: mTOR, p70S6K, AKT, and ERK1/2 levels predict sensitivity to mTOR and PI3K/mTOR inhibitors in human bronchial carcinoids. Endocr Relat Cancer 20: 463-475, 2013.

23. Travis WD, Brambilla E, Müller-Hermelink HK and Harris CC (eds): World HealthOrganization Classification of Tumours. Pathology and Genetics of Tumours of the Lung, Pleura, Thymus and Heart. IARC Press, Lyon, 2004.

24. Dabora SL, Jozwiak S, Franz DN, Roberts PS, Nieto A, Chung J, Choy YS, Reeve MP, Thiele E, Egelhoff JC, et al: Mutational analysis in a cohort of 224 tuberous sclerosis patients indicates increased severity of TSC2, compared with TSC1, disease in multiple organs. Am J Hum Genet 68: 64-80, 2001

25. Anagnostou VK, Bepler G, Syrigos KN, Tanoue L, Gettinger S, Homer RJ, Boffa D, Detterbeck F and Rimm DL: High expression of mammalian target of rapamycin is associated with better outcome for patients with early stage lung adenocarcinoma. Clin Cancer Res 15: 4157-4164, 2009.

26. Oh MH, Lee HJ, Yoo SB, Xu X, Choi JS, Kim YH, Lee SY, Lee CT, Jheon S and Chung JH: Clinicopathological correlations of mTOR and pAkt expression in non-small cell lung cancer. Virchows Arch 460: 601-609, 2012.

27. Righi L, Volante M, Rapa I, Tavaglione V, Inzani F, Pelosi G and Papotti M: Mammalian target of rapamycin signaling activation patterns in neuroendocrine tumors of the lung. Endocr Relat Cancer 17: 977-987, 2010.

28. Walch AK, Zitzelsberger HF, Aubele MM, Mattis AE, Bauchinger M, Candidus S, Präuer HW, Werner M and Höfler H: Typical and atypical carcinoid tumors of the lung are characterized by $11 \mathrm{q}$ deletions as detected by comparative genomic hybridization. Am J Pathol 153: 1089-1098, 1998.

29. Ullmann R, Schwendel A, Klemen H, Wolf G, Petersen I and Popper HH: Unbalanced chromosomal aberrations in neuroendocrine lung tumors as detected by comparative genomic hybridization. Hum Pathol 29: 1145-1149, 1998.

30. Zhao J, de Krijger RR, Meier D, Speel EJ, Saremaslani P, Muletta-Feurer S, Matter C, Roth J, Heitz PU and Komminoth P: Genomic alterations in well-differentiated gastrointestinal and bronchial neuroendocrine tumors (carcinoids): Marked differences indicating diversity in molecular pathogenesis. Am J Pathol 157: 1431-1438, 2000.

31. Ullmann R, Petzmann S, Klemen H, Fraire AE, Hasleton P and Popper HH: The position of pulmonary carcinoids within the spectrum of neuroendocrine tumors of the lung and other tissues. Genes Chromosomes Cancer 34: 78-85, 2002.

32. Warth A, Herpel E, Krysa S, Hoffmann H, Schnabel PA, Schirmacher P, Mechtersheimer G and Bläker H: Chromosomal instability is more frequent in metastasized than in non-metastasized pulmonary carcinoids but is not a reliable predictor of metastatic potential. Exp Mol Med 41: 349-353, 2009.

33. Katoh $Y$ and Katoh M: Comparative integromics on Angiopoietin family members. Int J Mol Med 17: 1145-1149, 2006.

34. Rosner M, Freilinger A, Lubec G and Hengstschläger M: The tuberous sclerosis genes, TSC1 and TSC2, trigger different gene expression responses. Int J Oncol 27: 1411-1424, 2005.

35. Pavel ME, Hainsworth JD, Baudin E, Peeters M, Hörsch D, Winkler RE, Klimovsky J, Lebwohl D, Jehl V, Wolin EM, et al: Everolimus plus octreotide long-acting repeatable for the treatment of advanced neuroendocrine tumours associated with carcinoid syndrome (RADIANT-2): A randomised, placebo-controlled, phase 3 study. Lancet 378: 2005-2012, 2011.

36. Fazio N, Granberg D, Grossman A, Saletan S, Klimovsky J, Panneerselvam A and Wolin EM: Everolimus plus octreotide long-acting repeatable in patients with advanced lung neuroendocrine tumors: Analysis of the phase 3, randomized, placebo-controlled RADIANT-2 study. Chest 143: 955-962, 2013.

37. Zatelli MC, Minoia M, Martini C, Tagliati F, Ambrosio MR, Schiavon M, Buratto M, Calabrese F, Gentilin E, Cavallesco G, et al: Everolimus as a new potential antiproliferative agent in aggressive human bronchial carcinoids. Endocr Relat Cancer 17: 719-729, 2010.

38. Iyer G, Hanrahan AJ, Milowsky MI, Al-Ahmadie H, Scott SN, Janakiraman M,Pirun M, Sander C, Socci ND, Ostrovnaya I, et al: Genome sequencing identifies a basis for everolimus sensitivity. Science 338: 221, 2012. 